\title{
CONDITION-BASED PROBABILISTIC SAFETY ASSESSMENT FOR MAINTENANCE DECISION MAKING REGARDING A NUCLEAR POWER PLANT STEAM GENERATOR UNDERGOING MULTIPLE DEGRADATION MECHANISMS
}

\author{
Seyed Mojtaba Hoseyni ${ }^{1}$, Francesco Di Maio' ${ }^{1}$, Enrico Zioo ${ }^{1,2}$ \\ ${ }^{1}$ Energy Department, Politecnico di Milano, Via La Masa 34, 20156 Milano, Italy \\ ${ }^{2}$ Chair on System Science and Energetic Challenge, Fondation Electricite de France (EDF), CentraleSupélec, \\ Université Paris Saclay, Gif-sur-Yvette 91190, France
}

\begin{abstract}
Condition-Based Probabilistic Safety Assessment (CB-PSA) makes use of inspections and monitoring information on Systems, Structures, and Components (SSCs) to update risk quantities. In this paper, we show the benefits of exploiting the condition-based estimates for taking maintenance decisions on a SSC undergoing multiple degradation mechanisms. To develop the method, we make reference to a spontaneous Steam Generator Tube Rupture (SGTR) Accident Scenario in a Nuclear Power Plant (NPP). The SG is susceptible to multiple degradation mechanisms, i.e., Stress Corrosion Cracking (SCC) and pitting. Tube plugging and Water Lancing and Chemical Cleaning (WL-CC) can be performed, before leading to a SGTR accident. Decisions must be taken on the maintenance strategy to perform at each inspection cycle. Results of a case study regarding SGTR show that the decisions based on the risk estimates provided by a CB-PSA approach allow controlling the SGTR risk at minimum maintenance cost.
\end{abstract}

Keywords: Probabilistic Safety Assessment (PSA), Condition-based PSA (CB-PSA), Maintenance, Nuclear Power Plant (NPP), Steam Generator (SG), SG tube rupture (SGTR), Pitting, Stress Corrosion Cracking (SCC). 


\section{Acronyms}

$\begin{array}{ll}\text { CB-PSA } & \text { Condition-Based Probabilistic Safety Assessment } \\ \text { CDF } & \text { Core Damage Frequency } \\ \text { ET } & \text { Event Tree } \\ \text { FT } & \text { Fault Tree } \\ \text { MLE } & \text { Maximum Likelihood Estimation } \\ \text { NHPP } & \text { Non-Homogeneous Poisson Processes } \\ \text { NPP } & \text { Nuclear Power Plant } \\ \text { NRC } & \text { US Nuclear Regulatory commission } \\ \text { OD } & \text { Operator Depressurization } \\ \text { PDF } & \text { Probability Density Function } \\ \text { PSA } & \text { Probabilistic Safety Assessment } \\ \text { PWR } & \text { Pressurized Water Reactor } \\ \text { RCS } & \text { Reactor Coolant System } \\ \text { RWST } & \text { Refueling Water Storage Tank } \\ \text { SCC } & \text { Stress Corrosion Cracking } \\ \text { SG } & \text { Steam Generator } \\ \text { SGTR } & \text { Steam Generator Tube Rupture } \\ \text { SSC } & \text { Systems, Structures, and Component } \\ \text { WL-CC } & \text { Water Lancing and Chemical Cleaning }\end{array}$

\section{Nomenclature}

\begin{tabular}{|c|c|}
\hline$t$ & Inspection cycle \\
\hline$a$ & Crack size in axial direction \\
\hline$x$ & Pit size in through-wall direction \\
\hline$K$ & Stress intensity factor \\
\hline$F$ & Geometric factor \\
\hline$d$ & Actual outer tube diameter \\
\hline$t_{s}$ & Actual thickness of the tube \\
\hline$\triangle P$ & Actual pressure difference between the inner and the outer sides of the SG tube \\
\hline$m$ & Expected number of pits initiated within the two successive inspection cycles $t$ and $t+1$ per SG \\
\hline$n$ & Number of pits that are initiated during the $t$-th cycle \\
\hline$S_{u}$ & Ultimate tensile strength \\
\hline$S_{y}$ & Yield strength \\
\hline$T_{m}$ & Expected mission time of SG \\
\hline$P_{b}$ & Burst pressure of an unflawed virgin tube \\
\hline$m_{b}$ & Bulging factor \\
\hline$\frac{d a}{d t}$ & Crack growth rate \\
\hline$f_{S G T R}$ & Frequency of SGTR occurrence \\
\hline$f_{T R}$ & Expected rupture frequency in cycle $t$ \\
\hline$N_{t b}(t)$ & Number of available tubes at cycle $t$ \\
\hline$d_{\text {nom }}$ & Nominal outside diameter of SG tube \\
\hline$t_{s, n o m}$ & Nominal thickness of SG tube \\
\hline$\Delta P_{\text {nom }}$ & Nominal pressure difference between the inner and the outer sides of the SG tube \\
\hline$W_{\text {nom }}$ & Nominal Power of the NPP \\
\hline$P_{\text {in, nom }}$ & Primary side pressure \\
\hline$P_{\text {out nom }}$ & Secondary side pressure \\
\hline$a_{\text {lim }}$ & Plugging limit caused by SCC cracks \\
\hline$a_{c r}$ & Critical crack length \\
\hline$\lambda(t)$ & Power law intensity function \\
\hline
\end{tabular}




$\begin{array}{ll}\Lambda(t) & \text { Expected number of initiated pits per SG } \\ g(x) & \text { Pit growth rate } \\ T W D_{\text {lim }} & \text { NRC Plugging limit with respect to Through Wall Depth } \\ T W D & \text { Through Wall Depth } \\ T W D_{c r} & \text { Failure threshold induced by pitting } \\ B_{c} & \text { Initial budget of each cycle } \\ S(t) & \text { Saved budget till cycle t } \\ B(t) & \text { Cumulative available budget at cycle t } \\ N_{p}(t) & \text { Number of tubes that should be plugged } \\ F(t) & \text { Number of tubes failed } \\ C D F_{S C C}(t) & \text { Core damage frequency if no plugging is enforced to counteract SCC } \\ C D F_{P}(t) & \text { Core damage frequency if no maintenance is enforced to counteract pitting } \\ C D F_{M D, S C C} & \text { Core damage frequency induced by SCC after maintenance decision is taken } \\ C D F_{M D, P} & \text { Core damage frequency induced by SCC after maintenance decision is taken } \\ C D F_{N R C, S C C} & \text { Core damage frequency from the enforcement of the NRC guidelines for maintenance } \\ C D F_{\text {static }} & \text { Core Damage Frequency calculated by the traditional PSA method } \\ - & \end{array}$

\section{INTRODUCTION}

Probabilistic Safety Assessment (PSA) is a formal and systematic approach to quantifying the risk of accidents in industrial systems and plants (NRC, 1983; NRC, 2011; Aven \& Zio, 2014; Zio, 2018). In current PSA practice, risk measures (such as Core Damage Frequency (CDF) of Nuclear Power Plants (NPPs)) are calculated by formal methods like Event Trees (ETs) and Fault Trees (FTs), based on the information available on the Systems, Structures, and Components (SSCs) prior to operation (i.e., generic data, codes and expert opinion) (NRC, 1975; Zio, 2007; ASME, 2009). Then, the risk assessment is updated with as specific information becomes available on the SSCs and their logical configuration (i.e. living PSA (IAEA, 1999)). Even though PSA is believed to reflect the actual status of the specific plant, it is mostly obtained from generic data of other plants similar by design, giving the picture of a prototypical plant, rather than the specific plant (Lewandowski, et al., 2016; Mandelli, et al., 2018), and does not fully account for the time processes of aging and degradation for updated risk measures estimations (Wang, et al., 2016; Alaswad \& Xiang, 2017; Liu, et al., 2017; Kim, et al., 2018).

On the other hand, digitization of industrial system and plants in the ongoing 4th industrial revolution brings new opportunities for aging and degradation monitoring by intelligent sensoring the SSCs and manipulation of the, therefore, available data (Zio, 2018). Inspection and/or monitoring data related to the SSCs status can allow specific condition-based updating of the risk measures quantification, within a risk assessment framework that can be called Condition-based PSA (CB-PSA) (Di Maio, et al., 2018; Zio, 2018). 
In this study, we show that the dynamic provision of condition-based risk measures estimates enables ranking the contribution to risk of different failure mechanisms affecting the SSCs and, consequently, prioritizing maintenance activities.

The methodology is presented with respect to a spontaneous Steam Generator Tube Rupture (SGTR) accident scenario that may occur in a Pressurized Water Reactor (PWR) (Di Maio, et al., 2018). Different degradation mechanisms that affect the SG tubes integrity are considered (Diercks, et al., 1999). Stress corrosion cracking (SCC) and pitting are eventually mentioned as the mechanisms most contributing to SGTR (Riznic, 2017). To counteract these degradation mechanisms, some maintenance strategies like tube plugging and Water Lancing and Chemical Cleaning (WL-CC) are commonly implemented (EPRI, 1996). These maintenance strategies are usually enforced according to regulatory guideline when corrosion reaches specific thresholds of developments (IAEA, 2006; IAEA, 2017). These strategies are found to be non-optimal (Wade, 1995): numerous cases of unnecessary plugging have been reported worldwide (EPRI, 2003) arguing that the risk related to possible NPP accidental scenarios generated by SG degradation is neither optimally controlled nor cost-efficient. In this study, we propose a decision framework, based on CB-PSA risk measures estimates for the operators to dynamically choose, at each inspection cycle, the optimal maintenance action to be undertaken to trade-off the risk of any accident that might be induced by a SGTR and the related maintenance cost. Indeed, realistic case of constrained budgetary resources is assumed, challenging for the operator choice on the maintenance strategy to be adopted (i.e. not only beneficial for safety but also economically affordable). The results show that the proposed framework enables the decision maker to predict the degradation evolution, predict the tube failure time, calculate the risk of SGTR failure due to the multiple degradation mechanisms and prioritize the maintenance actions, under budget constraints (Dube, et al., 2015). It is shown that the operators can optimally take the safest and most economic decision for maintenance, with respect to the state-of-practice NUREG report (NUREG/CR-6365, 1996).

The paper is organized as follows. Section 2 introduces the physical description of the spontaneous SGTR accident scenario, the SG model, and the SCC and pitting models. Section 3 illustrates the procedure for prioritization of the maintenance activities, based on the risk estimates provided by the CB-PSA approach. Section 4 presents the application to a case study, and a sensitivity analysis of the results. In Section 5, some conclusions are drawn. 


\section{THE SPONTANEOUS SGTR ACCIDENT SCENARIO}

The SGTR accident scenario is one of the most significant for NPPs safety, because it can lead to core damage (Diercks, et al., 1999). "The [steam generator tube] rupture can range from a failure of a small pit or crack in one tube to multiple, double-ended tube ruptures in a single generator or simultaneous ruptures in all steam generators." (quoting (NUREG/CR-6365, 1996)). It could lead to a modest release of radioactive material to the environment, but also, if not properly controlled, to severe core damage and substantial release of radioactive materials. In this study, the spontaneous SGTR accident scenario in a typical PWR (in our case, the Zion NPP, without loss of generality) is analyzed. It is assumed that tube ruptures are caused by multiple degradation mechanisms, specifically SCC and pitting, which are main contributors to tube ruptures (Wade, 1995), although with different risk implications (SCC may lead to large offsite radiological consequences, if operators action are not taken properly, whereas pitting does not pose significant consequences because it shows a very well-defined leak-before-break character (Laskowski \& Hudson 1986)). However, leak-beforebreak recognition requires the SG to be equipped with a leakage monitoring system to avoid the escalation of leaks into ruptures by prompt plugging before rupture (rather than relying only on periodic SG tubes inspections that may overlook leakages before rupture). In this methodological work, we conservatively neglect that the SG tubes can be monitored for leakage detection and consider SG tubes inspections as the only strategy to verify whether initiated pits are leak tight with Through-Wall Depth (TWD) not exceeding the pitting failure threshold (TWDcr), or that cracks length (a) does not exceed the SCC failure threshold (critical crack length (acr)).

In a traditional level 1 PSA, the SGTR accident scenario is modeled by an ET (Kloos \& Peschke, 2017) (see Fig. 1), where the core damage is one of the possible end state reached after the Initiating Event of SGTR is triggered, with frequency $f_{S G T R}$ estimated as:

$$
f_{S G T R}=\frac{N+1 / 2}{T}
$$

where $N=3$ is the number of SGTR occurrences in $T=499$ years of similar NPPs operations, irrespectively of the failure mechanism that has induced the SGTR (the interested readers are invited to refer to (Sattison \& Hall, 1990; Kim, et al., 2015) for further information). A simplified event tree with a spontaneous SGTR 
initiating event potentially leading to core damage is shown in Figure 1. Some safety functions/systems are considered and modelled to mitigate the SGTR effects, namely: the operator driven plant depressurization (OD), the Refueling Water Storage Tank (RWST) refill and, finally, the Reactor Coolant System (RCS) heat removal. If all the safety functions/systems are operational, the plant end state would result to be safe, whereas if any of them fails, core damage occurs. In the ET of Figure 1, the frequency of IE is computed from Eq. 1, resulting in a value of $7.01 \times 10^{-3}$ per reactor year and the probabilities of failure of operator depressurization OD, RWST and RCS are taken equal to $1.8 \times 10^{-4}, 2.4 \times 10^{-8}, 5.6 \times 10^{-5}$, respectively, from (Lewandowski, et al., 2016). The ET (static) approach of Figure 1 provides a Core Damage Frequency $C D F_{\text {static }}$ (constant in time) equal to $1.65 \times 10^{-6}$ per reactor year.

\begin{tabular}{|c|c|c|c|c|}
\hline $\begin{array}{c}\text { Spontaneous } \\
\text { SGTR }\end{array}$ & $\begin{array}{c}\text { Operator } \\
\text { Depressurization }\end{array}$ & $\begin{array}{c}\text { Refuelling Water } \\
\text { Storage Tank }\end{array}$ & $\begin{array}{c}\text { Reactor Coolant } \\
\text { System }\end{array}$ & End State \\
\cline { 1 - 3 } IE & OD & RWST & RCS & \\
\hline
\end{tabular}

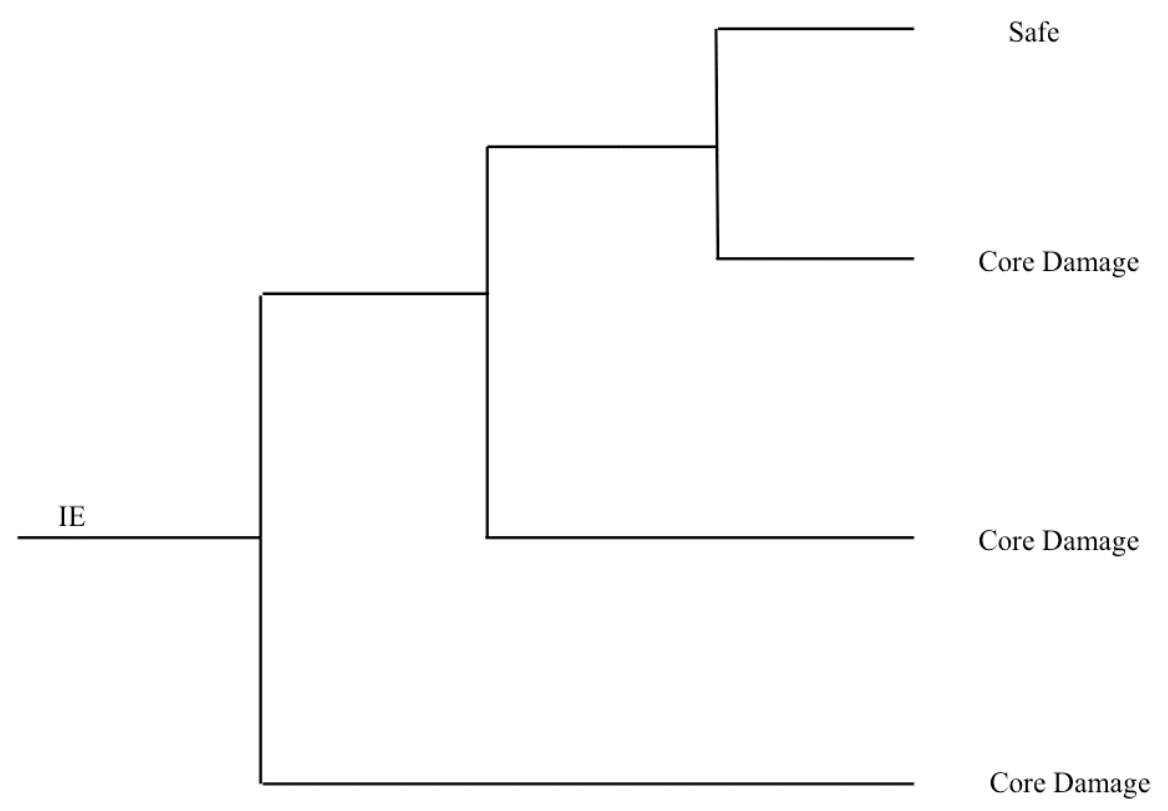

Figure 1: Simplified event tree for a spontaneous SGTR

In CB-PSA, we rely on models of the multiple degradation mechanisms (i.e. SCC and pitting, in this case) to calculate $f_{\text {SGTR: }}$ onset, formation, and propagation models of SCC, besides models of initiation and growth of the pits, are used to predict the degradation progression and, finally, to update the values of $f_{S G T R}$ and CDF. 


\subsection{The steam generator}

We consider the Zion PWR NPP, with SGs of $3.6 \mathrm{~m}$ of diameter and $21 \mathrm{~m}$ of height of Alloy 600 (as originally used in PWRs, but nowadays replaced by alloys more resistant to SCC). Each SG weighs $800 \mathrm{t}$ and consists of a bundle of $N_{t b}=3592$ inverted U-shaped tubes with design nominal outside diameter of $d_{\text {nom }}$ equal to 22.23 $\mathrm{mm}$. The design nominal thickness $t_{s, n o m}$ is equal to $1.27 \mathrm{~mm}$ to withstand a design nominal pressure difference on the tube wall equal to $\Delta P_{\text {nom }}=8.3 \mathrm{MPa}$. Details on the Zion NPP parameters are provided in Tables 1 and 2, together with their uncertainties (Lewandowski, 2013; Di Maio, et al., 2018).

Table 1: Parameters of the Zion NPP (Lewandowski, et al., 2016)

\begin{tabular}{|l|l|}
\hline NPP Operating Conditions & \\
\hline Nominal Power $W_{\text {nom }}$ & $1110 \mathrm{MW}_{\mathrm{e}}$ \\
\hline Primary side pressure $P_{\text {in,nom }}$ & $15.2 \mathrm{MPa}$ \\
\hline Secondary side pressure $P_{\text {out }, \text { nom }}$ & $6.9 \mathrm{MPa}$ \\
\hline SG Parameters & \\
\hline Number of tubes $N_{t b}$ & 3592 \\
\hline Material & Alloy $600 \mathrm{MA}$ \\
\hline Ultimate tensile strength (UTS) $S_{u}$ & $713 \mathrm{MPa}$ \\
\hline Yield strength (YS) $S_{y}$ & $362 \mathrm{MPa}$ \\
\hline
\end{tabular}

Table 2: Uncertainty in tubes parameters (Di Maio, et al., 2018)

\begin{tabular}{|l|l|l|}
\hline Parameter & Nominal Value & $\begin{array}{l}\text { Uncertainty } \\
\text { [uniform distribution] }\end{array}$ \\
\hline Outside diameter $d_{\text {nom }}$ & $22.23 \mathrm{~mm}$ & $+/-0.5 \mathrm{~mm}$ \\
\hline Thickness $t_{\text {s,nom }}$ & $1.27 \mathrm{~mm}$ & $+/-12.5 \%$ \\
\hline Nominal pressure difference $\Delta P_{n o m}$ & $8.3 \mathrm{MPa}$ & $+/-1 \mathrm{MPa}$ \\
\hline
\end{tabular}

\subsection{The SGTR degradation mechanisms}

The most significant degradation mechanism that can affect an SG leading to offsite radiological consequences that can be large, if actions are not properly taken, is SCC, which contributes to 60 to 80 percent of tubes defects requiring plugging. Pitting and fretting collectively account for 15 to 20 percent, whereas the remaining percentage is due to denting (Chatterjee \& Modarres, 2011)." 
In this work, we complement the analysis in (Di Maio, et al., 2018) by considering the simultaneous effects of multiple degradation mechanisms on the spontaneous SGTR accident scenario and investigating the maintenance activity to be performed at each $t$-th inspection cycle, here taken equal to two years, when inspection of the SG is also allowed due to core refueling. In line with (Karwoski, 2009), we assume the strictest sampling strategy for SG tube inspection, consisting in inspecting $100 \%$ of the SG tubes, at each inspection cycle $t=2$ years. Degradation in tubes is inspected with techniques that are assumed to be perfectly reliable. For the prevention of tube rupture, it is assumed that plugging and WL-CC are performed as maintenance strategies to counteract SCC and pitting, respectively. Alternatively, instead of plugging the tubes with medium-sized cracks, sleeving can be selected as another option of maintenance. However, since sleeving imposes higher operational costs than plugging (Wade, 1995), it is opted out of this research.

In this research, two different separate approaches are used to model the two main degradation mechanisms affecting SG performance, that are SCC and pitting. While the axial growth rate of the stress corrosion cracks is modeled by the Scott model (Cizelj, et al., 1995), the through-wall penetration rate of the pits is modeled by the Turnbull model (Turnbull, et al., 2006). Both degradation models describe a one-dimensional damage to SG tubes, modelling axial crack length growth and pit depth growth, respectively for SCC and pitting. The models describing for SCC and pitting are briefly presented in the following Sections.

\subsubsection{Stress corrosion cracking}

The tube cracking process induced by SCC can be divided into three phases: onset, formation, and propagation (Di Maio, et al., 2018). Crack onset and formation are modelled based on the real data collected in the Zion NPP (see (Lewandowski, et al., 2016)).

To estimate the onset probability of cracks in the SG, a Maximum Likelihood Estimation (MLE) approach is used to fit the available data collection (see (Lewandowski, et al., 2016) for further details) to a Weibull distribution, with Probability Density Function (PDF) of Eq. 2 whose parameters $b$ and $\lambda$ are equal to 0.3654 and 30.1609, respectively:

$f(t)=\frac{b}{\lambda^{b}} t^{b-1} e^{\left(\frac{-t}{\lambda}\right)^{b}}$

For cracks formation, it is assumed that in about 9.3 years (with standard deviation of 3.2 years), at the operating temperature of $330{ }^{\circ} \mathrm{C}$, axial microcracks reach a critical length of $0.1 \mathrm{~mm}$ at which propagation becomes faster (Cizelj, et al., 1995). Following the Scott model (Cizelj, et al., 1995), which is an empirical 
model that depends on the material property, tube dimension and pressure difference of the tube bundles, the crack growth rate $\frac{d a}{d t}$ which grows in the axial direction is modeled as in Eq. 3:

$\frac{d a}{d t}=\alpha_{s} \cdot\left(K-K_{t h}\right)^{\beta_{s}}$

where $\alpha_{s}, \beta_{s}$ and $K_{t h}$ are constant values, and the stress intensity factor $K$ is derived from Eq.4:

$K=F \frac{\Delta P . d}{2 t_{s}} \sqrt{\frac{\pi a}{2}}$

where $F$ is a geometric factor, $\Delta P$ is the actual pressure difference between the inner and the outer sides of the SG tube, $d$ is the actual outer tube diameter, and $t_{s}$ is the thickness of the tube (see Table 2 for $\Delta P_{\text {nom }}, d_{n o m}$, and $t_{s, n o m}$, the design nominal values of the actual values $\Delta P, d$, and $t_{s}$ that may be different than the design nominal values because of uncertainty (as listed in Table 2)). The design nominal values of the crack growth parameters are listed in Table 3, along with their uncertainty bounds:

Table 3: Parameters of crack growth used in the Scott model (Di Maio, et al., 2018)

\begin{tabular}{|c|c|c|c|}
\hline Parameter & Minimum & Maximum & Nominal \\
\hline$\alpha_{s}$ & $2.5 \mathrm{e}-2$ & $3.1 \mathrm{e}-2$ & $2.8 \mathrm{e}-2$ \\
\hline $\mathrm{K}_{\mathrm{th}}(\mathrm{MPa} \sqrt{m})$ & 8 & 10 & 9 \\
\hline$\beta_{s}$ & 1.07 & 1.25 & 1.16 \\
\hline $\mathrm{F}$ & - & - & 0.93 \\
\hline
\end{tabular}

According to NUREG report (NUREG/CR-6365, 1996), the SG tubes are plugged when the Through Wall Depth (TWD) exceeds $40 \%$ of the nominal tube wall thickness $t_{s, n o m}$. In (Lewandowski, et al., 2016), it is assumed that plugging is necessary when the depth-to-length ratio $\left(t_{s} / a\right)$ of the crack is equal to $1 / 3$ : being $t_{s, n o m}$ $=1.27 \mathrm{~mm}$ and the maximum $T W D_{\text {lim }}=0.51 \mathrm{~mm}$, we assume a plugging limit with respect to crack length $a_{\text {lim }}$ equal to $1.52 \mathrm{~mm}$ (see Figure 2).Therefore, when $a$ reaches $a_{\text {lim }}=1.52 \mathrm{~mm}$, the tube where that crack has propagated must be plugged as soon as it is detected when inspected, to avoid reaching the critical crack length $a_{c r}$ (i.e., the spontaneous SGTR is induced). It is worth mentioning that $a_{c r}$ is calculated from Eq. 5:

$\Delta P=\frac{P_{b}}{m}=\frac{P_{b}}{0.614+0.481 \phi+0.386 e^{-1.25 \phi}}$

where $P_{b}$ is the burst pressure of an unflawed virgin tube, $m_{b}$ is the bulging factor, and $\phi=\frac{1.82 a_{c r}}{\sqrt{2 d-t_{s}}}$ (NUREG/CR-6664, 2000). The critical crack length $a_{c r}$, therefore, changes in time depending on the actual 
work load of the plant and the pressure difference, $W$ and $\Delta P$, respectively (that, incidentally, also influences $K$, and in turn, $\frac{d a}{d t}$ ). Therefore, we can claim that plugging may not be always the optimal decision, because costly and not always effective for controlling the SGTR occurrence (EPRI, 1996): Indeed, plugging reduces the heat transfer surface and the primary system mass flow rate, and increases the actual $\Delta P$ (facilitating the crack propagation as shown in (Di Maio, et al., 2018)); large amount of plugging also reduces the reactor nominal power and generates economic losses (Pla, et al., 2013). This problem is overlooked by regulation but can be improved by the application of CB-PSA to support maintenance decisions, as we shall see in what follows. In practice, the optimized condition-based plugging strategy introduced in (Di Maio, et al., 2018), consists in plugging tubes when the identified crack at inspection time $t$ is calculated to exceed $a_{c r}$ within the $t$-th cycle and $t+1$-th cycle of length 2 years with more than $1 \%$ probability (see (Di Maio, et al., 2018) for further details), instead of when the cracks exceed the plugging limit $a_{\text {lim }}$, as regulation would suggest.

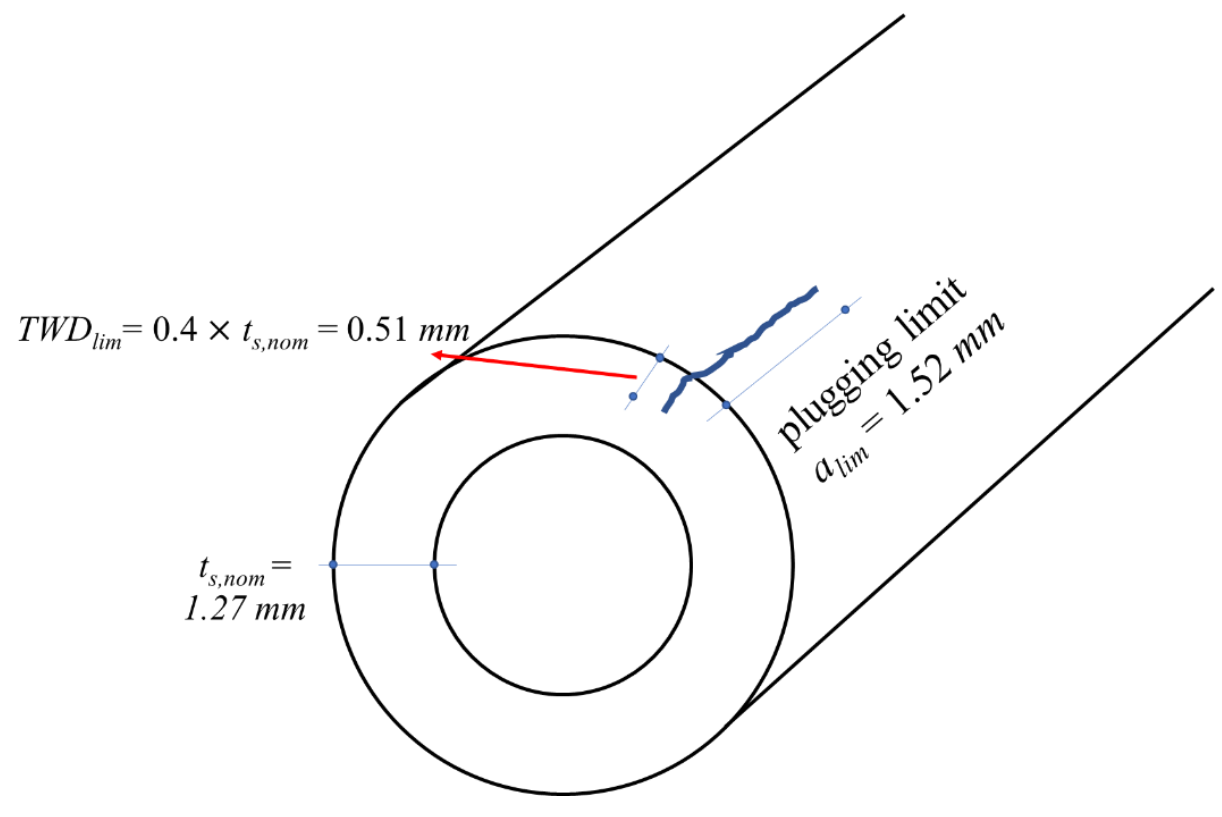

Figure 2: Plugging limit of a crack induced by SCC

\subsubsection{Pitting}

Pitting is a local corrosion mechanism which typically occurs at the tube surface where pre-existing defects are incidentally generated by surface machining and whose growth is accelerated by impurities (Valor, et al., 2007). Pitting can be modeled as a two steps stochastic process: pit initiation and pit growth (Ishihara, et al., 2008; Navidi \& Shayer, 2018). Pit initiates when breakdown occurs in the passive layer of the metal surface and consequent metal dissolution takes place, whereas pit growth occurs when corrosion radially penetrates the tube wall and creates small holes (Hong, 1999; Turnbull, et al., 2006). 
For pit initiation, stochastic models are proposed based on Non-Homogeneous Poisson Processes (NHPP): let the number of initiated pits $N(t)$ at time $t$ (for all the SG tubes surface area) follow a NHPP (Datla, et al., 2008; Yuan, et al., 2009; Zhou \& Zhai, 2011) with a power law intensity function $\lambda(t)=\alpha t^{\beta-1}$, where $\alpha$ and $\beta$ are the scale and shape parameters taken equal to 0.0014 and 4.526, respectively, as in (Datla, et al., 2008) where the pitting initiation process is modeled for a SG that has similar specifications (height, length, surface area, ...) and properties (material, working pressure and temperature, ...) to those of Zion NPP. The expected number $\Lambda(t)$ of initiated pits at time $t$ is:

$\Lambda(t)=\int_{0}^{t} \lambda(s) d s=\frac{\alpha}{\beta} t^{\beta}$

and the expected number $m$ of pits initiated within the two successive inspection cycles $t+1$ and $t$ (of length 2 years):

$m=\Lambda(t+1)-\Lambda(t)=\frac{\alpha}{\beta}\left((t+1)^{\beta}-t^{\beta}\right)$

The number $n$ of pits that are initiated during the $t$-th cycle follows a Poisson distribution:

$\operatorname{Pr}\{N(t+1)-N(t)=n\}=\exp (-[\Lambda(t+1)-\Lambda(t)]) \frac{[\Lambda(t+1)-\Lambda(t)]^{n}}{n !}$

Figure 3 shows the cumulative number of pits initiated at each inspection cycle $t$, and the 5\% and 95\% percentiles (i.e. a two-sided $90 \%$ confidence interval).

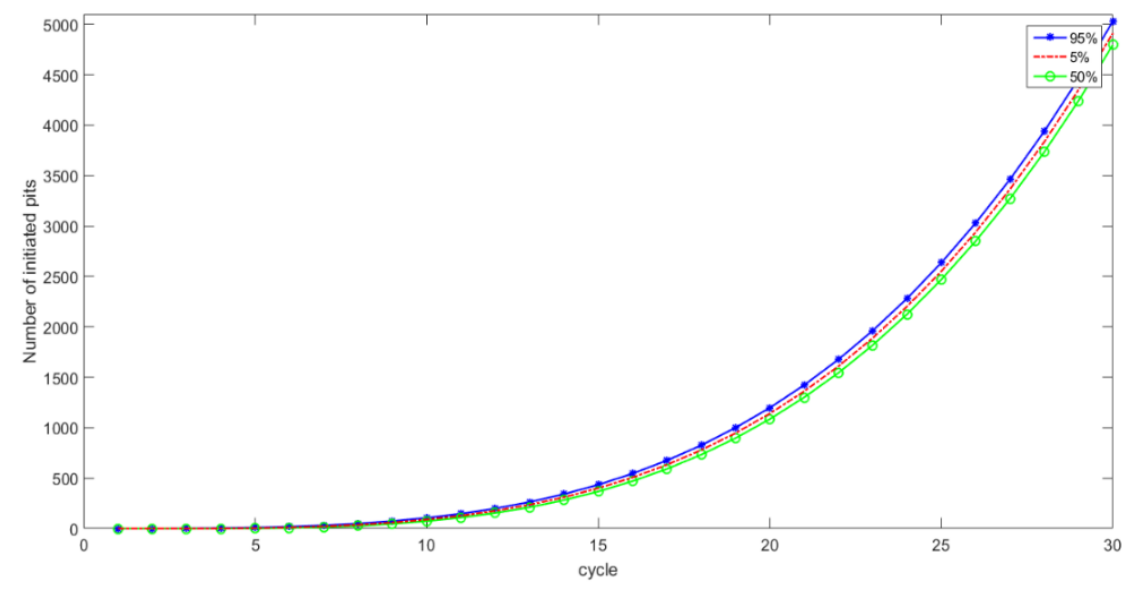

Figure 3: A two-sided 90\% confidence interval for the number of initiated pits, at each SG inspection cycle

Following the initiation of a small pit, we use the model in (Turnbull, et al., 2006) to simulate the pit growth in time. The pit growth is modelled as a one-dimensional radial degradation in the wall depth direction. As soon as the through-wall depth of the pit exceeds a specific threshold, failure of the tube will occur (Datla, et al., 2008). The radial growth rate $g(x)$ of the pit size $x[\mathrm{~m}]$ in through-wall direction is equal to: 
$\frac{d x}{d t}=g(x)=\delta \gamma^{\frac{1}{\delta}} x^{\left(1-\frac{1}{\delta}\right)}$

$x=\gamma t^{\delta}$

where $\gamma$ and $\delta$ are fitting parameters experimentally calculated: $\gamma$ is assumed to be distributed as a truncated positive normal distribution with mean value equal to 0 and standard deviation equal to $1.36 \mathrm{e}-5$, and $\delta$ is taken as a constant equal to 0.064 , (Luo, et al., 2016)).

Plugging must be enforced when the Through Wall Depth (TWD), $x / t_{s, n o m}$ reaches $40 \%$ (NUREG/CR-6365, 1996), meaning that plugging is done when $x$ penetrates $40 \%$ of the tube thickness $t_{s, n o m}$ to avoid it reaches the failure threshold $T W D_{c r}=95 \%$ obtained by reference to the operational experience in (Datla, et al., 2008): a small pit that may exceed the failure threshold $T W D_{c r}$ would trigger a SGTR accident scenario (NUREG/CR6365, 1996). Moreover, regulation recommends performing Water Lancing and Chemical Cleaning (WL-CC) at least once in $T_{m}$, not only for reducing the corrosive environment during SG operation, due to the large concentration of chlorides and sulfites in deposit, but also for improving the heat transfer rate of the tubes (EPRI, 1996). By WL-CC, sludges are removed and, consequently, pits initiation is temporarily slowed down to $80 \%$ (EPRI, 2003; Datla, et al., 2008; Yuan, et al., 2009). However, there is no theoretical evidence that changes to the SG operational conditions can modify the growth parameters (Navidi \& Shayer, 2018), although cracks formed by pitting propagate slower than those induced by SCC. Then, in this work, we assume pitting is controlled only by WL-CC (and not also by plugging).

\section{MAINTENANCE OPTIMIZATION BASED ON CB-PSA}

SG degradation can be counteracted by plugging the tubes (Diercks, et al., 1999) or by WL-CC (P.J.Millett \& Welty, 2012). These strategies can be enforced at each inspection time $t$, but at a cost. We denote the budgetary constraint as $B_{c}$ for each cycle and as $B(t)$ for the cumulative available budget at cycle $t$. The risk measures updated at each inspection by the CB-PSA are utilized to evaluate the risk due to the different degradation mechanisms and prioritize the activities of maintenance. On the basis of the CDF estimates relative to SCC and pitting provided by CB-PSA at each inspection, the operator chooses the balance of plugging and WL-CC to perform on the SG tubes, so as to trade off cost (up to the maximum affordable cost $B(t)$ ) and risk at each $t$ th cycle.

The cost of WL-CC is assumed to be 5 times the initial budget $\left(B_{c}\right)$ of each cycle (Burgmayer, 2001); the 
plugging cost depends on the number of tubes that must be plugged: if the number of plugged tubes is smaller than 300 tubes it is equal to $0.2 B_{c}$, otherwise the cost is $0.6 B_{\mathrm{c}}$ (Wade, 1995).

The novel framework (sketched in Figure 4) for simultaneously considering pitting and SCC and deciding on the most proper budget of maintenance activities, consists of four nested steps, namely degradation modelling, risk prioritization, cost assessment and decision making. In practice, starting from inspection cycle $t=1$

1. Set the operational conditions that are expected to be experienced by the SG up to the next cycle $t+1$, i.e., the number of available tubes $N_{t b}$, the actual pressure difference $\Delta P$, the water chemistry and the sludge content (that affect $\alpha$ and $\beta$ of Eq. 5);

- a.1. Define $a_{c r}$, depending to the operational conditions (see Eq. 5);

- a.2. Simulate the SCC microcracks generation and their propagation up to the next cycle $t+1$ (see Eqs. 2 \& 3): First, the probability of a crack onset and formation (i.e., the probability that the crack length reaches the limit beyond which it propagates) is calculated by the convolution of the two distributions of onset (Eq. 2) and formation $(\mathrm{N} \sim(9.3,3.2)$ years). Then, the crack is propagated by Eq. 3 up to the next cycle $t+1$;

- a.3. Simulate the SCC progression of the existing cracks up to the next cycle $t+1$ (see Eq. 3);

- a.4. Calculate the number of tubes $N_{p}(t)$ that should be plugged, according to the optimized condition-based plugging strategy presented in (Di Maio, et al., 2018) (i.e., tubes are plugged only if the crack length $x$ exceeds $a_{c r}$, with probability larger than $1 \%$ );

- a.5. Calculate the number of tubes $F(t)$ with cracks exceeding $a_{c r}$ if no plugging is enforced and the corresponding $C D F_{S C C}(t)$, as follows (Di Maio, et al., 2018):

$$
C D F_{S C C}(t)=f_{S G T R}(t) \times \frac{C D F_{\text {static }}}{f_{\text {SGTR }}}
$$

Assuming $N_{t b}(t)$ is the number of tubes available at cycle $t$, and these tubes are independent, $f_{\text {SGTR }}(t)$ is the frequency of SGTR occurrence at cycle $t$ :

$$
f_{S G T R}(t)=1-\prod_{N_{t b}(t)}\left(1-f_{T R}(t)\right)
$$

where $f_{T R}$ is the expected tube rupture frequency between cycles $t$ and $t+1$ :

$$
f_{T R}(t)=\frac{F(t)+\frac{1}{2}}{t \cdot N_{t b}(t)}
$$




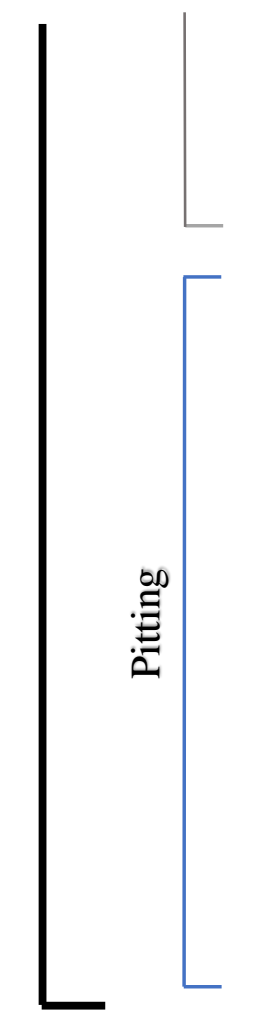

$F(t)$ with cracks exceeding $a_{c r}$. Since $F(t)$ and $N_{t b}(t)$ are changing in time based on the maintenance strategy that is enforced, the value of $f_{T R}(t)$ should be accordingly updated, which results in the change of $f_{S G T R}(t)$ in time.

- b.1. Define $T W D_{c r}$ depending on the operational conditions;

- b.2. Simulate pits initiation and their stochastic growth up to the next cycle $t+1$ (see Eqs. 6, 7 , and 8);

- b.3. Simulate the progression of the existing pits up to the next cycle $t+1$ (see Eq. 9);

- b.4. Calculate the number of tubes $F(t)$ with pits exceeding $T W D_{c r}$ if no WL-CC is enforced and compute the $C D F_{P}(t)$, as follows:

$$
C D F_{P}(t)=f_{S G T R}(t) \times \frac{C D F_{\text {Static }}}{f_{S G T R}}
$$

where $f_{S G T R}(t)$ is calculated as in Eqs. $12 \& 13$ and is updated in each cycle based on the current properties of the tubes, as explained in section a.5.

c.1. Compare $C D F_{S C C}(t)$ and $C D F_{P}(t)$ for risk prioritization:

- c.2. If $C D F_{S C C}(t) \leq C D F_{\text {static }}$ or $C D F_{P}(t) \leq C D F_{\text {static }}$, there is no need to perform plugging or WL-CC, respectively.

$\checkmark$ if $C D F_{S C C}(t) \geq C D F_{P}(t)$ and $C D F_{S C C}(t)>C D F_{\text {static }}$, priority goes to plugging to counteract SCC;

d.1. if $N_{p}(t) \geq 300$, then the maintenance cost is $C(t)=0.6 B_{c}$.

Cost Assessment
- d.2. else if $N_{p}(t)<300$, then $C(t)=0.2 B_{c}$.

- d.3. set saved budget $S(t)=B(t)-C(t)$, if it is decided to perform plugging; then, if $S(t) \geq$ $5.0 B_{c}$, WL-CC can be performed.

$\checkmark$ else if $C D F_{S C C}<C D F_{P}$ and $C D F_{P}>C D F_{\text {static }}$, then priority goes to WL-CC to counteract pitting.

- d.4. Set $C(t)=5 B_{c}$

Cost Assessment
- d.5. set $S(t)=B(t)-C(t)$, if it is decided to perform WL-CC.

- d.6. Then, if $N_{p}(t) \geq 300$ and $S(t) \geq 0.6 B_{c}$, plugging can be performed.

- d.7. else if $N_{p}(t)<300$ and $S(t) \geq 0.2 B_{c}$, plugging can be performed. 
e.1. Take decision:

$\checkmark \quad$ If priority is for plugging and $B(t) \geq C(t)$, then perform plugging and set $S(t)=B(t)-C(t)$.

- Then, if no WL-CC has been performed before, and $S(t) \geq 5 B_{c}$, perform WLCC, and set $S(t)=S(t)-5 B_{c}$ and $C(t)=C(t)+5 B_{c}$.

$\checkmark \quad$ If priority is for WL-CC and $B(t) \geq C(t)$ and no WL-CC has been performed before, then perform WL-CC and set $S(t)=B(t)-C(t)$.

- then, if $N_{p}(t) \geq 300$ and $S(t) \geq 0.6 B_{c}$, perform plugging, and set $S(t)=S(t)$ $0.6 B_{c}$ and $C(t)=C(t)+0.6 B_{c}$.

- else, if $N_{p}(t)<300$ and $S(t) \geq 0.2 B_{c}$, plugging can be performed, and set $S(t)$ $=S(t)-0.2 B_{c}$ and $C(t)=C(t)+0.2 B_{c}$.

There may be cases when the budget is not sufficient for performing maintenance. Therefore, the maintenance is postponed to the next inspection cycle, accepting the risk of not performing maintenance.

2. At the end of each inspection cycle $t$, set $B(t+1)=S(t)+B_{c}$ and $t=t+1$ to repeat the framework for the next cycles, depending on the decisions taken, by setting:

- the number of available tubes $N_{t b}$ (as in Eq. 15) if plugging is performed.

$$
N_{t b}(t+1)=N_{t b}(t)-N_{p}(t)
$$

where $N_{p}(t)$ is the number of plugged tubes.

- the pressure difference $\Delta P$ (as in Eq. 16) if plugging is performed.

$$
\Delta P(t+1)=P_{\text {in }}\left(1+\frac{N_{p}(t)}{N_{t b}(t)} \times 0.4\right) P_{\text {out }, \text { nom }}
$$

because $\Delta P$ increases when the number of plugged tubes $N_{p}(t)$ increases.

- the number of initiated pits based on the improved environment after cleaning, which affects $\alpha$ and $\beta$ of Eqs. 6 and 7 if WL-CC is performed 


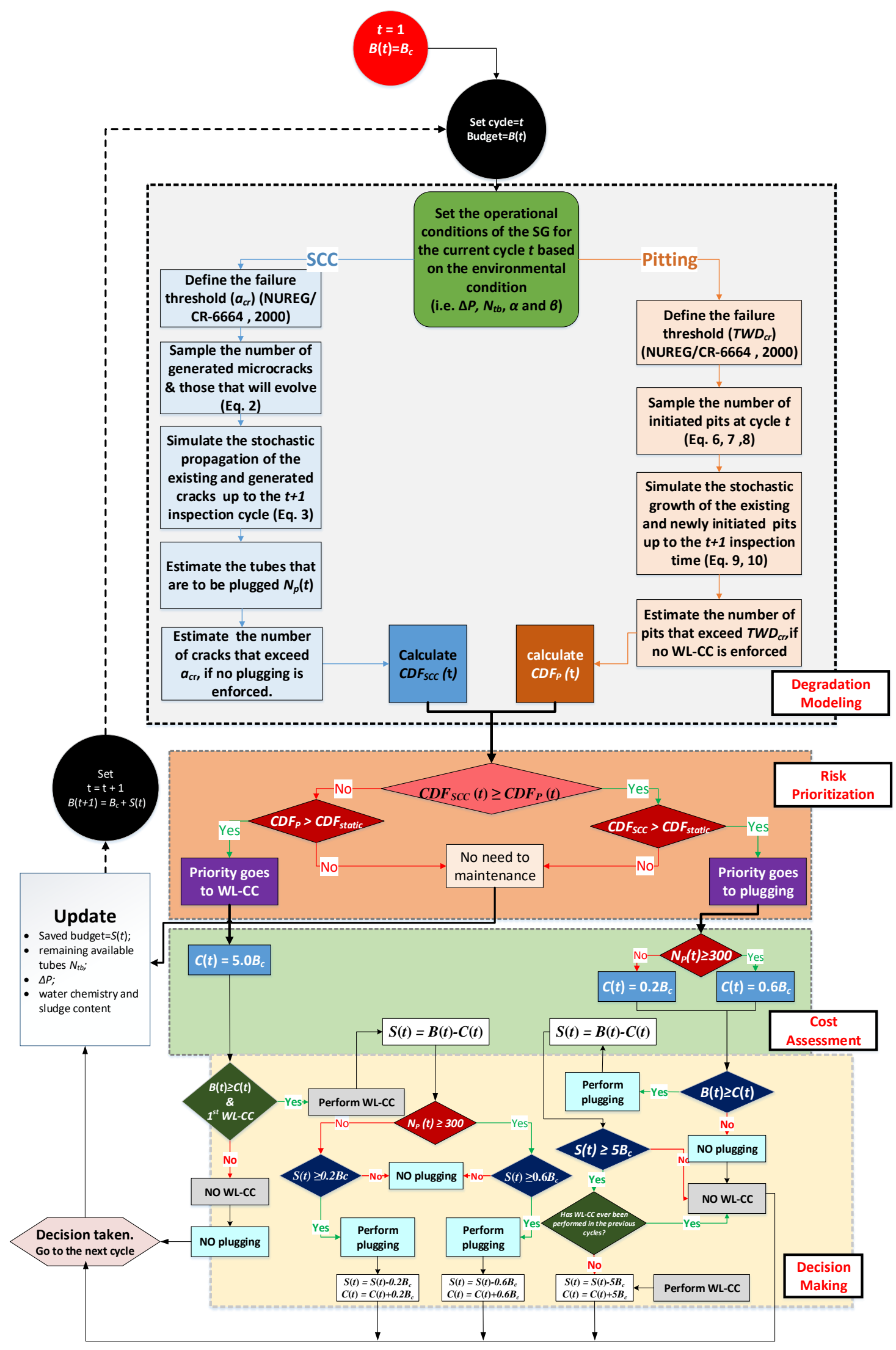

Figure 4: Flowchart of the risk-informed maintenance decision strategy 


\section{CASE STUDY}

The SG of the Zion NPP with the properties described in Section 2.2 is considered. At each cycle, (inspection time) $t$, starting from $t=1$, with the operational conditions of the SG in Tables 1 and 2, the failure thresholds of $a_{c r}$ and $T W D_{c r}$ are set. The generation of microcracks and their growth progression are simulated up to the next cycle $t+1$ for SCC. At the same time, the pit initiation and stochastic growth of pits are stochastically simulated up to cycle $t+1$. The CDF estimates obtained at each inspection cycle, with the maintenance managed as explained in Section 3, are plotted in Figure 5: the bold continuous line is the estimated $C D F_{S C C}(t)$ and the dashed line is $C D F_{P}(t)$. For comparison, $C D F_{\text {static }}$ is plotted in the dashed-dotted line. The values of $C D F_{S C C}(t)$ and $C D F_{P}(t)$ are calculated for each cycle to prioritize the maintenance activity, and the associated costs are used to inform the decision maker regarding the maintenance to be performed to counteract the most dangerous degradation. It should be noted that the value of $C D F_{S C C}(t)$ increases in time until the $7^{\text {th }}$ cycle and, then, decreases until it reaches an almost constant value at the last cycles. This is due to the fact that most of the cracks due to SCC are generated at the earliest cycles of the SG operation, as shown in Figure 3 of (Di Maio et al 2018) and, then, the probability of crack onset in a given cycle reduces with time. Therefore, as the operational time increases, the probability of crack onset and formation reduces as well. On the other hand, tubes that were plugged do not impair the SG integrity, resulting, as a whole, in the $C D F \operatorname{scc}(t)$ decreasing in time. 


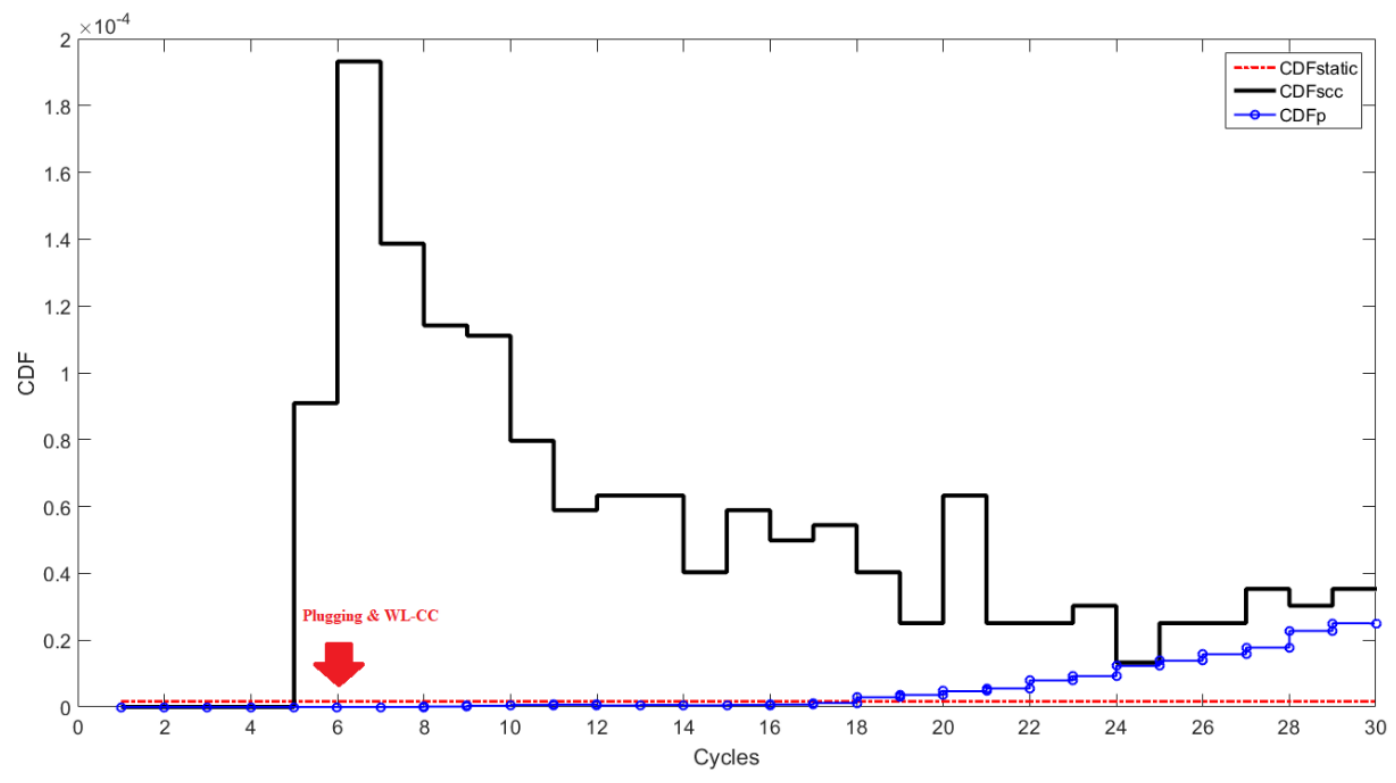

Figure 5: CDF estimates when CB-PSA estimates are used to prioritize maintenance

From inspection cycle $t=1$ to $t=4, C D F_{S C C}(t)<C D F_{\text {static }}$ and $C D F_{P}(t)<C D F_{\text {static }}$; therefore, there is no need to perform any maintenance. On the other hand, at inspection time $t=5, C D F_{S C C}(t)>C D F_{P}(t)$ making plugging the prioritized maintenance to counteract SCC. At cycle $t=6$, plugging is still the preferred maintenance activity, but since the available budget $B(t=6)=5.8 B_{c}$ is enough for both plugging and WL-CC $\left(\operatorname{cost} \mathrm{C}(t=6)=5.2 B_{c}\right)$, both maintenances activities are performed, reducing the savings to $S(t=6)=0.6 B_{c}$ as shown in Figure 6 where the total maintenance cost for each cycle $C(t)$ (continuous line), the cumulative savings $S(t)$ accumulated up to the current cycle $t$ (dashed line), and the available budget of each cycle $B(t)$ (dotted line) are shown. At any following cycles plugging is performed. 


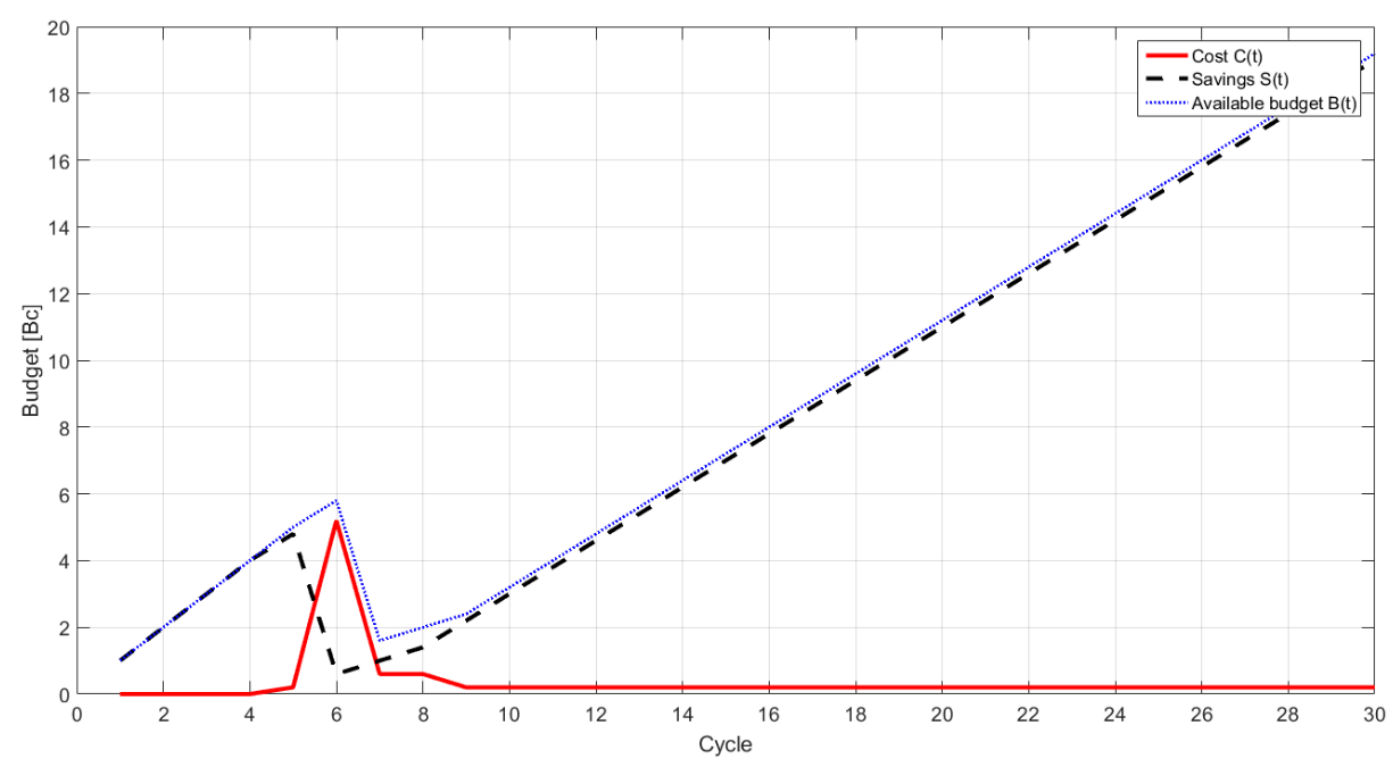

Figure 6: Comparison of the total cost of maintenance for each cycle $C(t)$ (continuous line), the cumulative saved money accumulated from previous cycles $S(t)$ (dashed line) and the available budget of each cycle $B(t)$.

Figure 7 shows the ratio between $C(t)$ and $B(t)$ (continuous line) and $S(t)$ and $B(t)$ (dashed-dotted line). At cycle $6,90 \%$ of the available budget $B(t)$ is spent for maintenance. This budget is the result of savings accumulated in the first 5 cycles and is more than $90 \%$ of the available budget (dasheddotted line from $t=1$ to 5$)$.

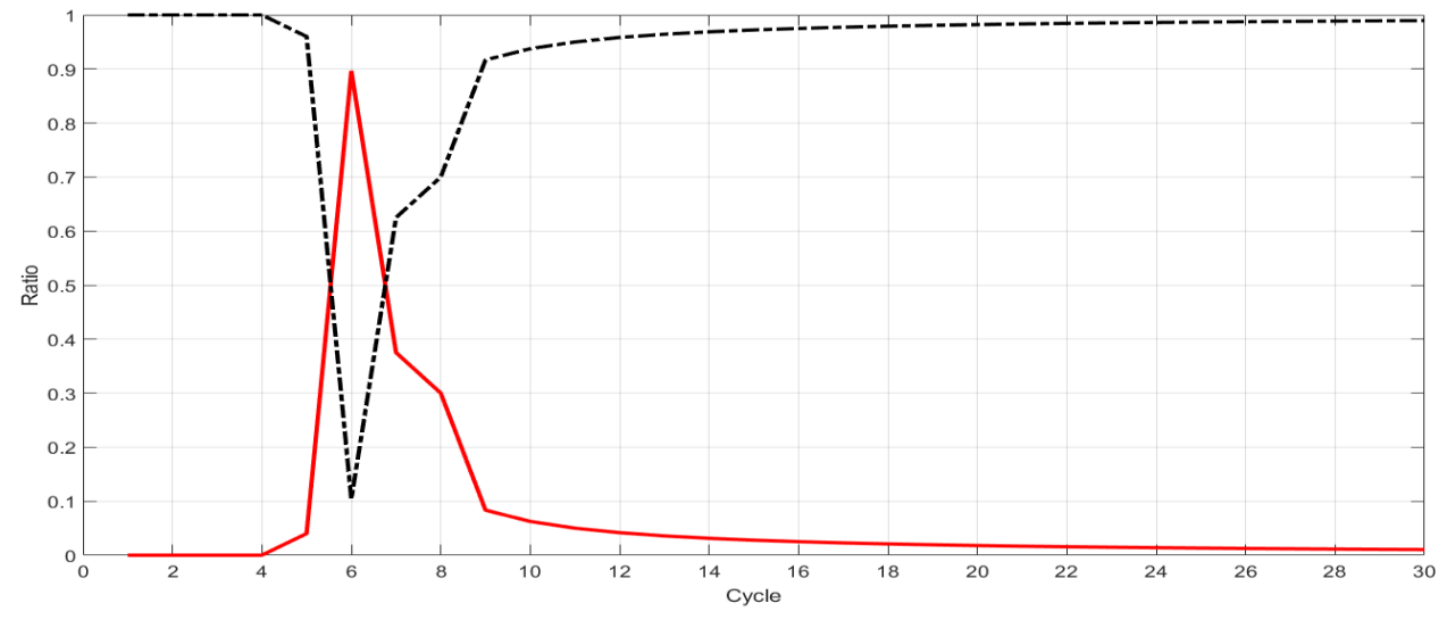

Figure 7: The ratio of risk-informed maintenance cost to available budget $C(t) / B(t)$ (continuous line) and savings per available budget $S(t) / B(t)$ (dashed-dotted line).

Figure 8 shows the resulting $C D F_{M D, S C C}$ of SCC (dashed line with crosses) and $C D F_{M D, P}$ (dashed line) of pitting upon enforcement of the optimal maintenance at each cycle $t$ and compares it with the traditional $C D F_{\text {static }}$ (dashed-dotted line), the $C D F_{N R C, S C C}$ (continuous line), that would result from the 
enforcement of the NRC guidelines for plugging (i.e. exceeding the crack length of $1.52 \mathrm{~mm}$ in case of SCC) and the $C D F_{N R C, P}$ (continuous line with circles) resulting from performing one WL-CC in the lifetime of the SG at cycle 15 . It can be seen that: i) $C D F_{M D, S C C}$ is zero at all cycles because of implementing plugging that never lets a crack to reach the failure threshold $a_{c r}$, ii) $C D F_{M D, P}$ initially increase and, then, decreases at cycle 11 thanks to the WL-CC performed at $6^{\text {th }}$ cycle, iii) the positive effect of WL-CC at the $15^{\text {th }}$ cycle for the NRC method is visible in $C D F_{N R C, P}$, after the $20^{\text {th }}$ cycle, iv) $C D F_{N R C, P}$ and $C D F_{N R C, S C C}$ are larger than $C D F_{\text {static }}$, because they are the realistic risk measures updated by the plant conditions after each inspection cycle, v) for SCC, the $C D F_{M D, S C C}$ values with maintenance performed based on the CB-PSA results is always lower than its corresponding value $C D F_{N R C, S C C}$, where maintenance follows the NRC recommendations. For pitting, $C D F_{M D, P}$, is always lower than its corresponding value $C D F_{N R C, P}$, until the $25^{\text {th }}$ cycle, and almost equal to it at the next cycles. These evidences show the beneficial effects of the proposed CB-PSA framework for maintenance decision making.

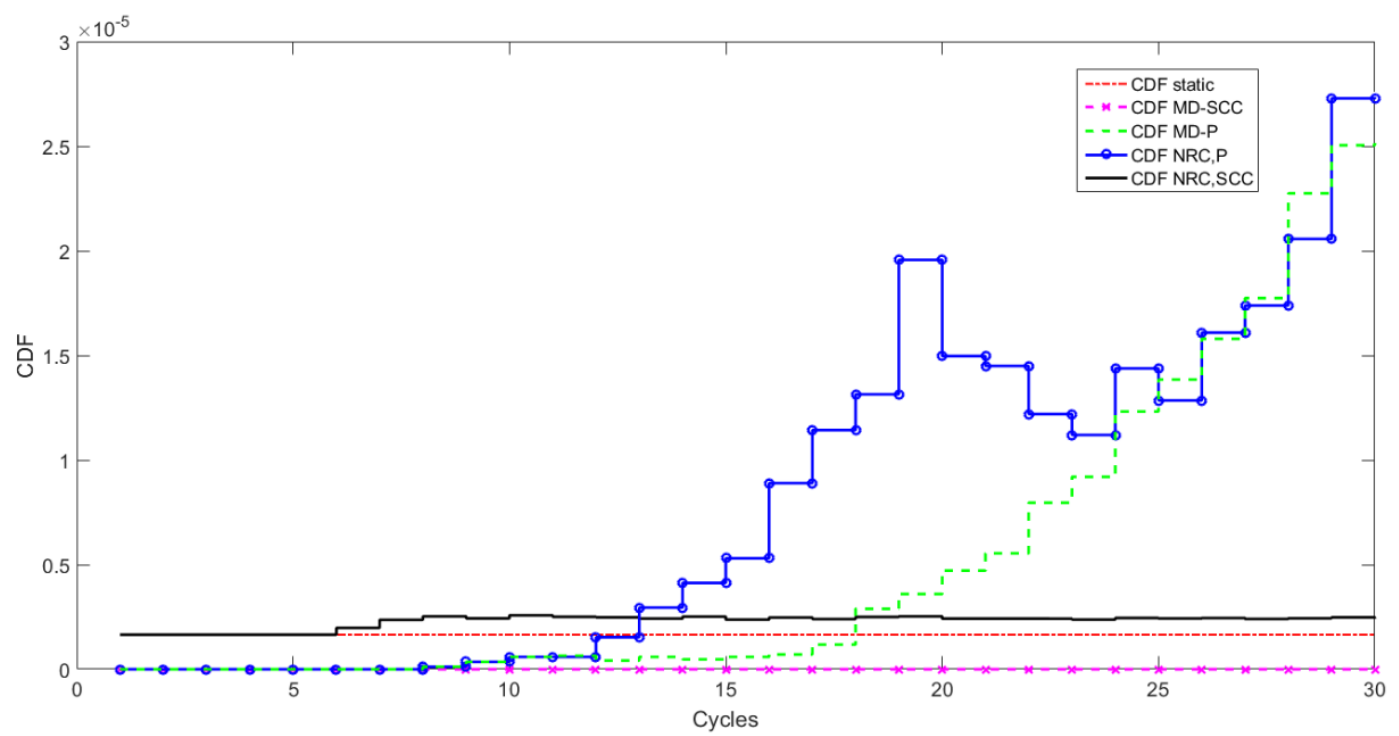

Figure 8: Comparison of CDF for multiple degradation mechanisms with different maintenance strategies.

Figure 9 shows the cumulative CDF when both pitting and SCC are considered as SGTR initiating events, and NRC procedures (NUREG/CR-6365, 1996) (solid line) or CB-PSA driven maintenance decisions (dashed line) are followed. The proposed methodology controls better the escalation of the $\mathrm{CDF}$ as the NPP ages $\left(C D F_{N R C}\right.$ is larger than $\left.C D F_{M D}\right)$. It should also be noted that $C D F_{N R C}$ is 
dynamically changing and at most cycles is larger than $C D F_{\text {static }}$ (dashed-dotted red line), because the $C D F_{N R C}$ is realistically estimated with updated plant conditions. As previously shown in (Di Maio, et al., 2018), risk measures are underestimated by the traditional static method (i.e. $C D F_{\text {static }}$ ).

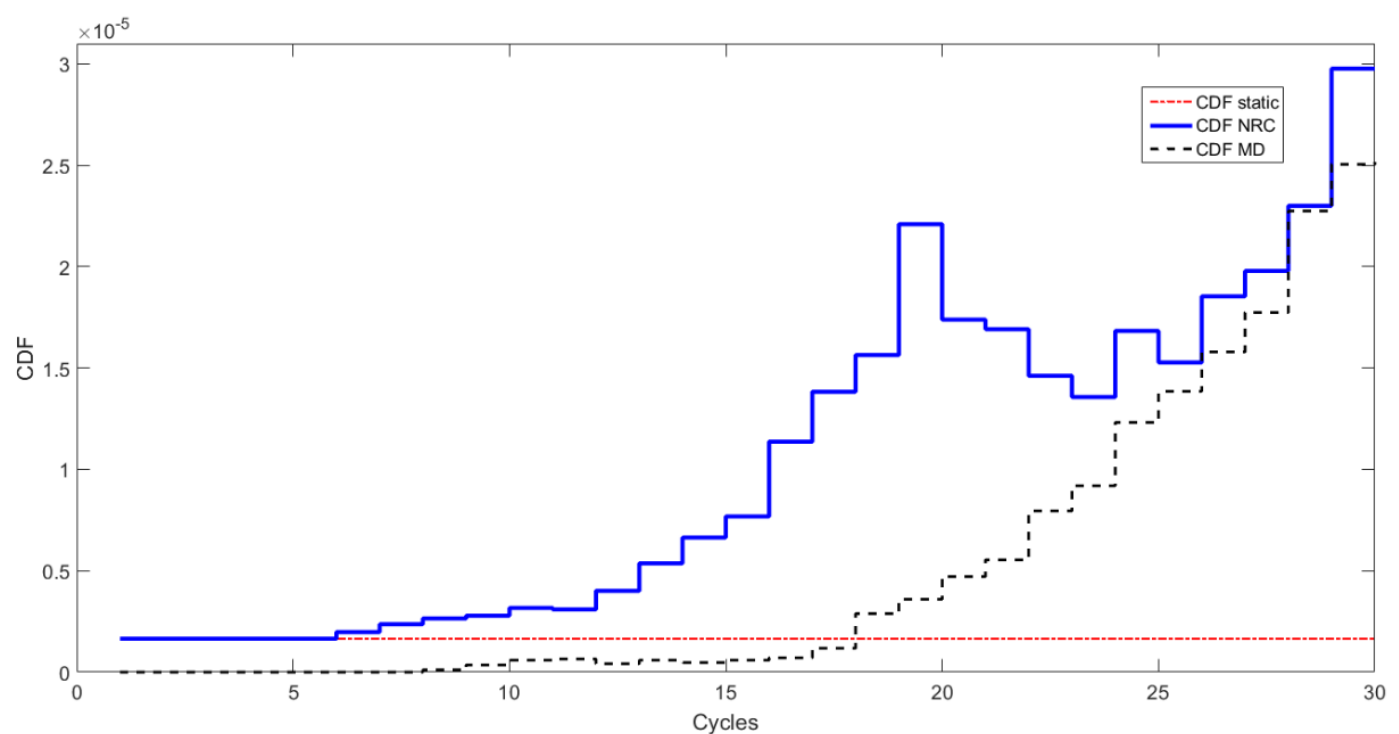

Figure 9: Comparison of CDF of the NRC procedure (solid line) with the CB-PSA driven maintenance decisions (dashed line).

Moreover, following the NRC guidelines (NUREG/CR-6365, 1996): i) the tubes should be plugged when the cracks exceed the failure threshold for both degradation mechanisms of pitting and SCC and ii) at least one WL-CC is recommended within the lifetime of the SG (here set to be performed at cycle 15). The advantage of the proposed methodology over the conventional NRC method, in terms of cost, is presented in Figure 10, where enforcing the NRC method gives $65 \%$ higher total cumulative maintenance cost $\sum_{t=1}^{30} C(t)$ at the end of the NPP life in comparison to our proposed maintenance methodology. Therefore, the proposed method not only leads lower risk than the NRC requirement (see Figure 9), but also smaller cost. 


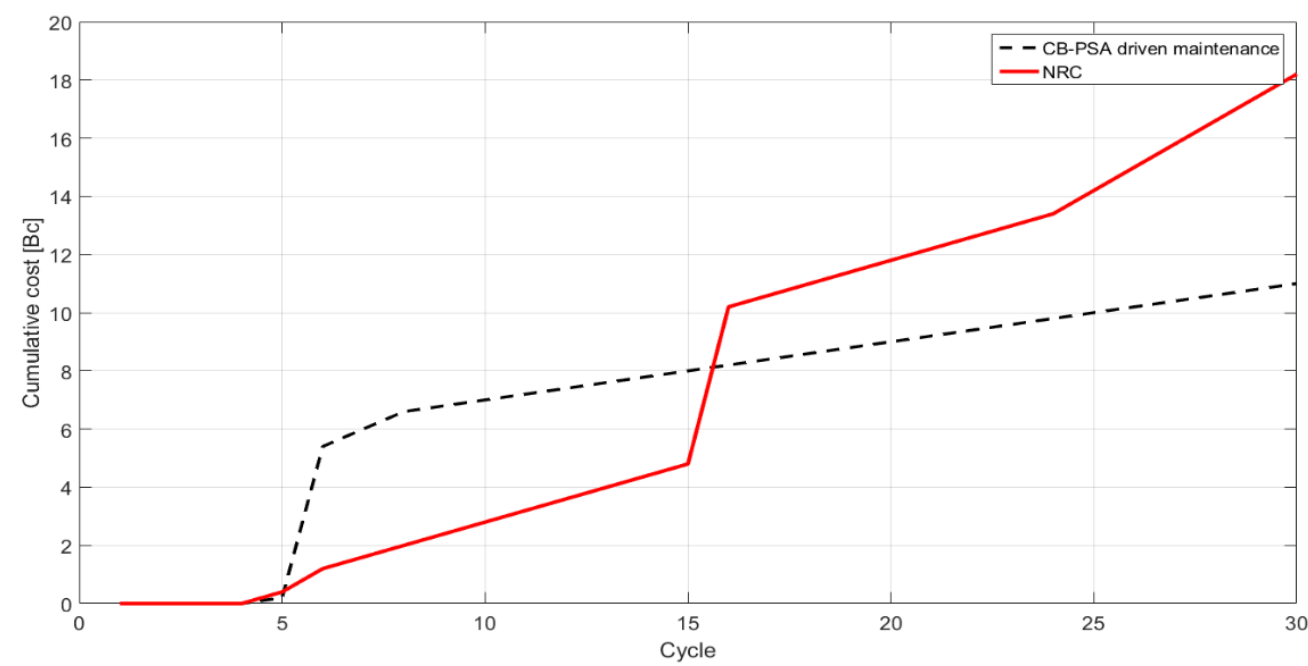

Figure 10: Comparison between the cumulative cost of maintenance in CB-PSA driven maintenance and NRC enforcement.

\subsection{Sensitivity analysis}

In this Section, we analyze the effects of different hypotheses of the cost model as summarized in Table 4.

Table 4: Different cost hypotheses

\begin{tabular}{|l|l|l|l|}
\hline Maintenance type & Smallest cost & Average cost & Largest cost \\
\hline WL-CC & $5.0 B_{c}$ & $7.5 B_{c}$ & $10.0 B_{c}$ \\
\hline Plugging more than 300 tubes in a cycle & $0.6 B_{c}$ & $0.8 B_{c}$ & $1.0 B_{c}$ \\
\hline Plugging less than 300 tubes in a cycle & $0.2 B_{c}$ & $0.35 B_{c}$ & $0.5 B_{c}$ \\
\hline
\end{tabular}

A combination of 27 possible cost models are generated and used as hypotheses within the framework of maintenance decision making described in Section 3.

Figure 11 shows the cost of maintenance for the 27 cases. The Figure shows the ratio of the cumulative cost at cycle $t\left(\sum_{i=1}^{t} C(i)\right)$ to the cumulative budget at cycle $t\left(B_{c} \times \sum_{i=1}^{t} i\right)$. Generally speaking, it can be seen that the sooner WL-CC is performed the lower probability of SGTR failure due to pitting, although WL-CC is only affordable for 6 out of the 27 cost models at nearest eligible time which is cycle 6 (i.e., those with cheapest WL-CC cost equal to $5.0 B_{c}$ (solid lines)). In particular, as shown in Figure 11, for two cases WL-CC is affordable at cycle 7 (diamond-lines), for one case at cycle 9 (green circled-lines), continuing postponing it (dashed lines), cycle by cycle, until the most 
expensive case where the WL-CC can be performed only at cycle 18 (line with crosses).

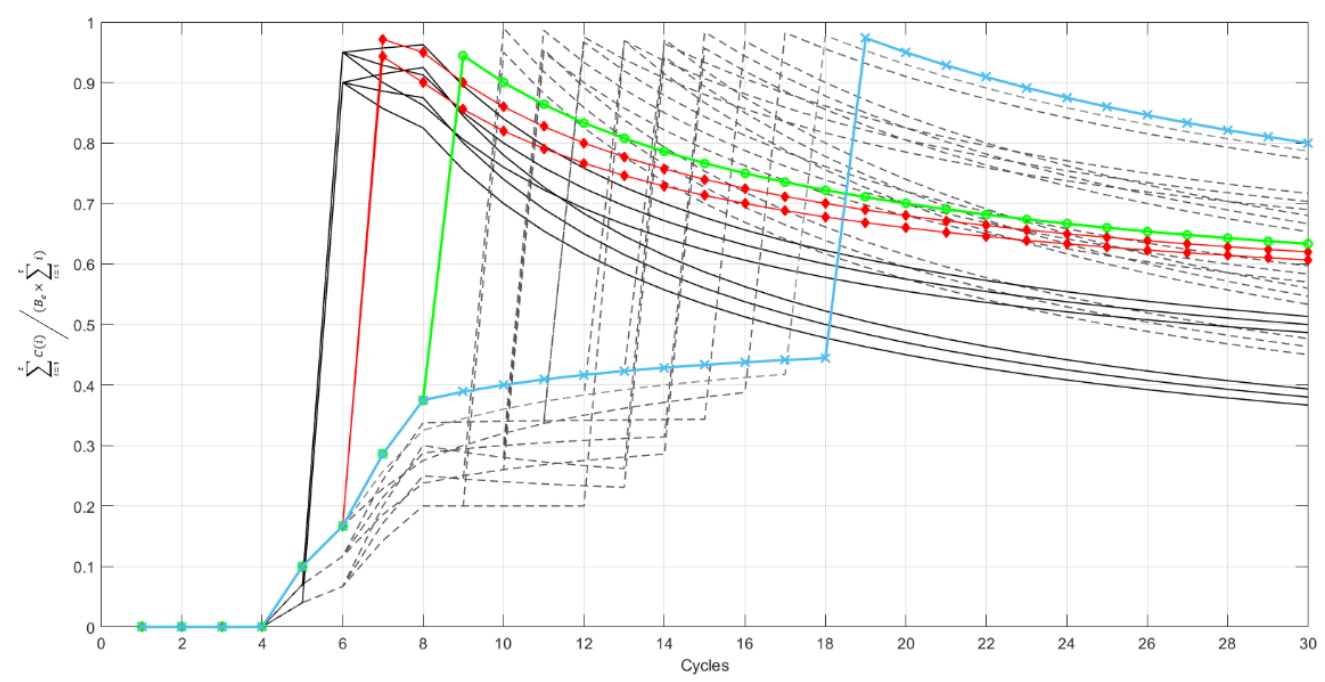

Figure 11: The ratio of the cumulative maintenance cost at each cycle t to the cumulative budget at each cycle $t$, for 27 cost scenarios.

The $C D F_{M D, P}$ values for different cost scenarios of Figure 11 are shown in Figure 12, with the same line styles in both Figures. The cheapest cost scenarios are related to the six cases where WL-CC is performed at cycle 6 with the solid line representing the lowest $C D F_{M D, P}$. In the remaining cases, since WL-CC is postponed due to shortage of funding, the SG is exposed to an increase of pitting-initiated SGTR scenarios and, consequently, $C D F_{M D, P}$ increases as shown in Figure 12: the diamond line represents the second cheapest two scenarios, the circled line represents the third cheapest one scenario and, finally, the crossed line represents the highest cost scenario, which also has the highest $C D F_{M D, P}$ 


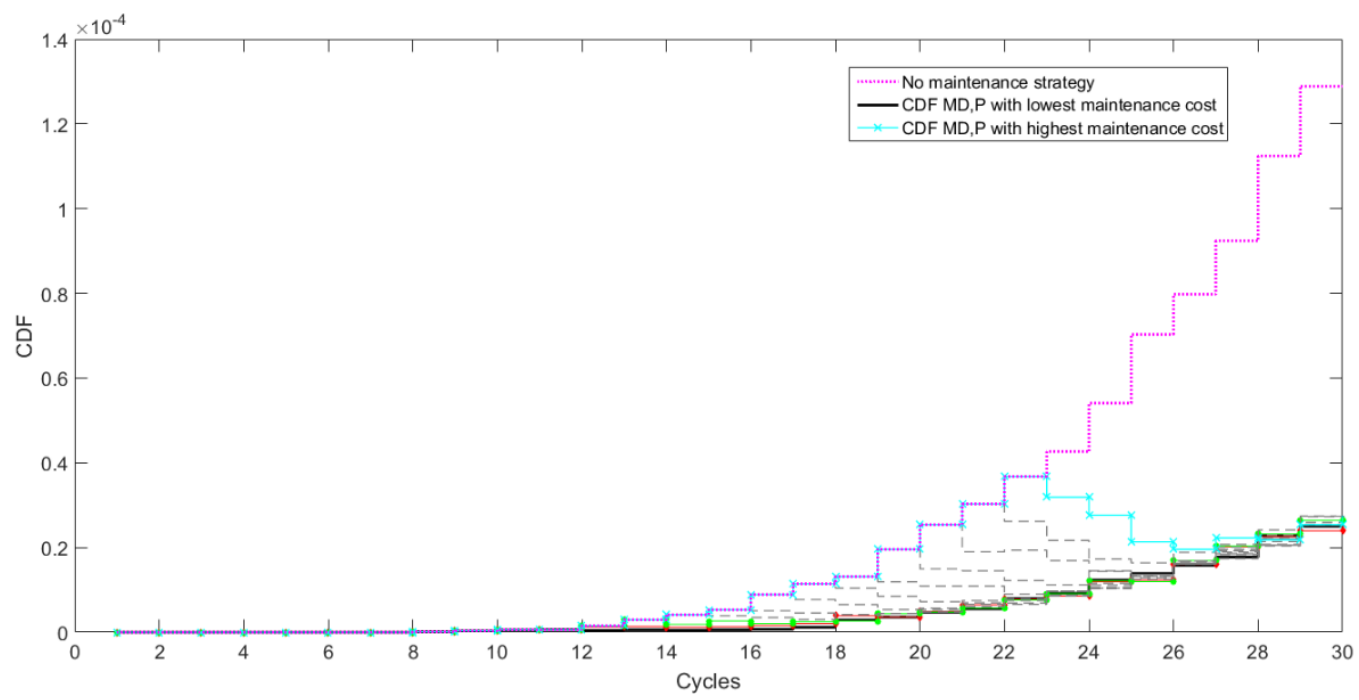

Figure 12: $C D F_{M D, P}$ values resulted from 27 maintenance cost scenarios

Figure 13 compares the cost of the NRC maintenance (solid lines) with that of our proposed method (dotted lines) in the 27 different cost scenarios, in terms of the ratio of the cumulative cost at cycle $t\left(\sum_{i=1}^{t} C(i)\right)$ to the cumulative budget at cycle $t\left(B_{c} \times \sum_{i=1}^{t} i\right)$. As it can be seen, in 12 out of 27 cases the NRC maintenance is not affordable because the available budget (dashed line) is exceeded. On the contrary, the proposed methodology manages the maintenance cost in all the possible cost scenarios.

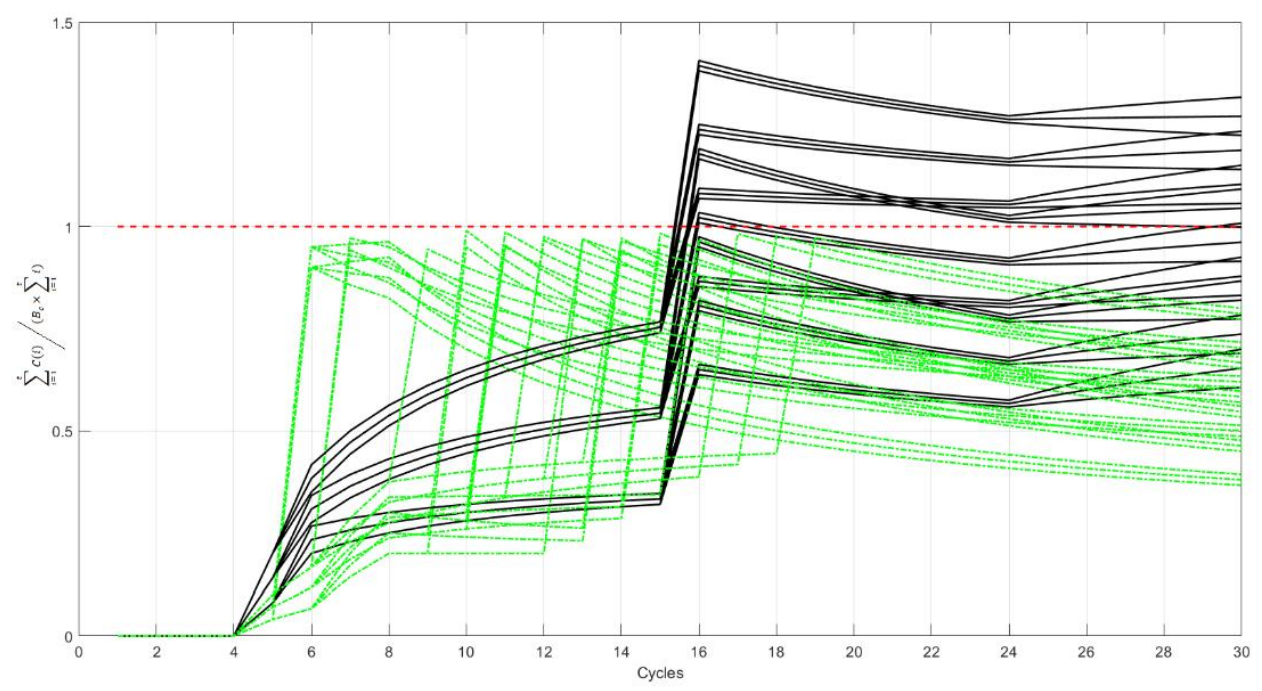

Figure 13: The ratio of the cumulative maintenance cost at each cycle t to the cumulative budget at each cycle $t$, for 27 cost scenarios using CB-PSA decision maintenance (dotted lines) and the NRC method (solid lines). Dashed line is the threshold when the costs exceed the budget.

Figure 14 shows the integral CDF of pitting and SCC. Only 3 out of 27 cases of very expensive maintenance costs (crossed line and two dashed lines) result in CDF values higher than for the NRC guided maintenance 
(dotted line), but this latter is not affordable (Figure 13). In all other cases, the total CDF is less than the NRC's value.

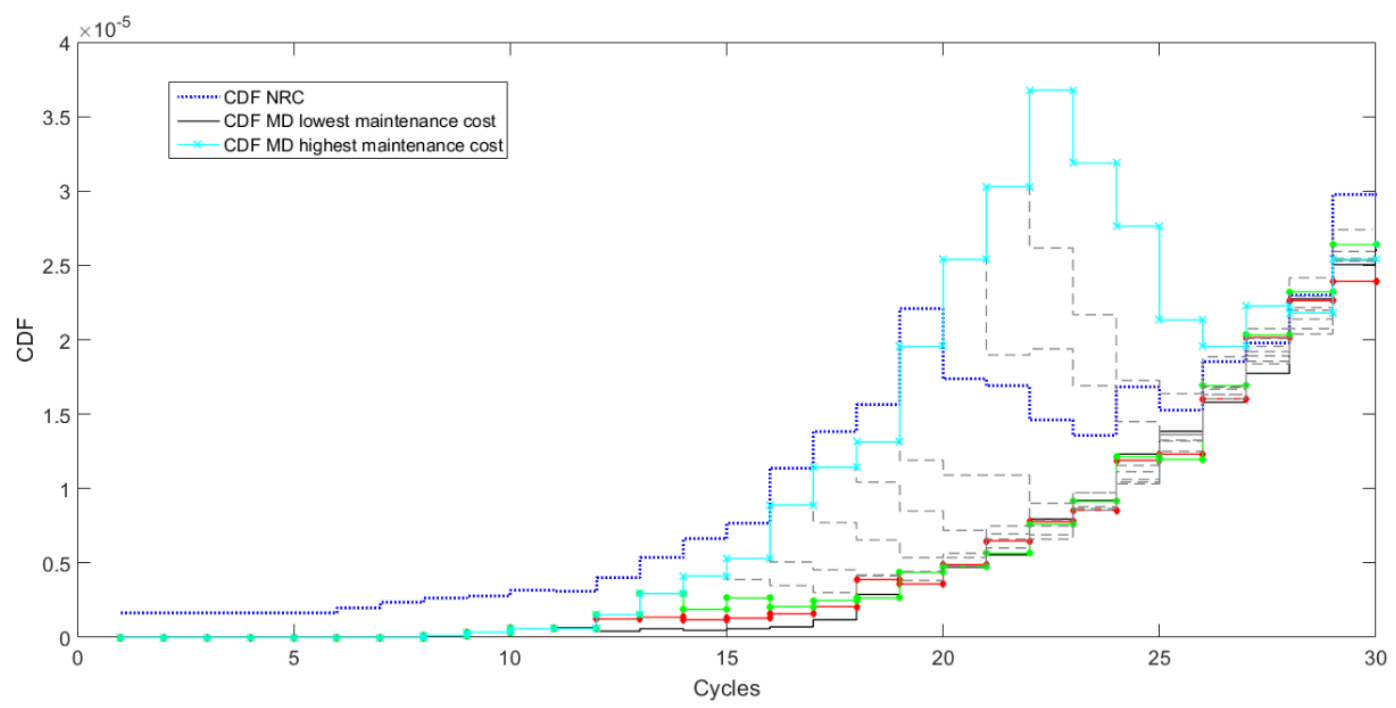

Figure 14: Comparison of CDF values of the NRC procedure with that of CB-PSA driven maintenance decisions in different cost scenarios.

\section{CONCLUSIONS}

In this paper, condition monitoring is integrated in the systematic framework of PSA for updating accident probabilities and estimating their consequences based on the predicted degradation states. This allows a "living" prioritization of the risks that impact the lifecycle asset management in the short, middle, and long terms, and a proactive management of them by allowing the decision makers to take real-time decisions on the optimal maintenance strategy to prevent accidents and balance the maintenance budget expenditure. It is worth mentioning that any suggested decision by CB-PSA framework should be ultimately verified with the Regulatory Guides (RG) (e.g., RG 1.174 in the US) for regulatory approval. To show the methodology, the CB-PSA has been used to inform maintenance decisions (plugging and WL-CC) for controlling the risk of SGTR initiated by multiple degradation mechanisms, namely SCC and pitting.

Based on the results of the application on the case study of multiple SG tubes degradation mechanisms with Zion NPP parameters, it can be concluded that the proposed methodology can not only significantly reduce the risk of SGTR but also lower the maintenance cost. 


\section{ACKNOWLEDGMENT}

This research is funded by INAIL - Grant 3158/2017 - 3rd Call SAF€RA.

\section{REFERENCES}

(Alaswad \& Xiang, 2017), Alaswad, S. \& Xiang, Y., 2017. A review on condition-based maintenance optimization models for stochastically deteriorating system. Reliability Engineering \& System Safety, Volume 157, pp. 54-63.

(ASME, 2009), ASME, 2009. Standard for Level 1/Large Early Release Frequency Probabilistic Risk Assessment for Nuclear Power Plant Applications, New York: American Society of Mechanical Engineers.

(Aven \& Zio, 2014), Aven, T. and Zio, E., 2014. Foundational issues in risk assessment and risk management. Risk Analysis, 34(7), pp.1164-1172.

(Burgmayer, 2001), Burgmayer, P. R., 2001. Method of sludge removal in pressurized water nuclear reactors. Patent No. WO2001011935 A2.

(Chatterjee \& Modarres, 2011), Chatterjee, K. \& Modarres, M., 2011. A Probabilistic Physics of Failure Approach to Prediction of Steam Generator Tube Rupture Frequency. Wilmington, NC.

(Cizelj, et al., 1995), Cizelj, L., Mavko, B., H., R.-O. \& Brücker-Foit, A., 1995. Propagation of stress corrosion cracks in steam generator tubes. International journal of pressure vessels and piping, 63(1), pp. 35-43.

(Datla, et al., 2008), Datla, S. V., Jyrkama, M. I. \& Pandey, M. D., 2008. Probabilistic modelling of steam generator tube pitting corrosion. Nuclear Engineering and Design, Volume 238, p. 1771-1778.

(Di Maio, et al., 2018), Di Maio, F., Antonello, F. \& Zio, E., 2018. Condition-based probabilistic safety assessment of a spontaneous steam generator tube rupture accident scenario. Nuclear Engineering and Design, Volume 326, pp. 41-54.

(Diercks, et al., 1999), Diercks, D., Shack, W. \& Muscara, J., 1999. Overview of steam generator tube degradation and integrity issues. Nuclear Engineering and Design, Volume 194, p. 19-30.

(Dube, et al., 2015), Dube, D. A., Chapman, J. R., Austgen, K. R. \& Butler, J. C., 2015. Risk-informed prioritization of nuclear power plant issues and activities, PSA 2015.

(EPRI, 1996), EPRI, 1996. Steam Generator Reference Book, Palo Alto, CA: Electric Power Research Institute.

(EPRI, 2003), EPRI, 2003. Steam Generator Degradation Database (SGDD), Version 5.0, Palo Alto, CA.: Electric Power Research Institute (EPRI).

(Hong, 1999), Hong, H. P., 1999. Application of the stochastic process to pitting corrosion. Corrosion 55.1, 55(1), pp. 10-16.

(IAEA, 1999), IAEA, 1999. Living probabilistic safety assessment (LPSA). IAEATECDOC-1106, Vienna: International Atomic Energy Agency. 
(IAEA, 2006), IAEA, 2006. Integrated approach to optimize operation and maintenance costs for operating nuclear power plants (IAEA-TECDOC-1509), Vienna, Austria: International Atomic Energy Agency.

(IAEA, 2017), IAEA, 2017. Handbook on Ageing Management for Nuclear Power Plants, Vienna: International Atomic Energy Agency.

(Ishihara, et al., 2008), Ishihara, S. et al., 2008. On the initiation and growth behavior of corrosion pits during corrosion fatigue process of industrial pure aluminum. International Journal of Fatigue, 30(9), pp. 1659-1668.

(Karwoski, 2009), Karwoski, K., 2009. Steam generator tube integrity requirements and operating experience in the United States. s.1., 6th International CNS Steam Generator Conference.

(Kim, et al., 2018), Kim, H., Kim, J. \& Heo, G., 2018. Failure rate updates using condition-based prognostics in probabilistic safety assessments. Reliability Engineering \& System Safety, Volume 175, pp. 225-233.

(Kim, et al., 2015), Kim, H. et al., 2015. Reliability data update using condition monitoring and prognostics in probabilistic safety assessment. Nuclear Engineering and Technology, 47(2), pp. 2042011.

(Kloos \& Peschke, 2017) Kloos, M. \& Peschke, J., 2017. IDPSA approach to assess the potential of a thermally induced steam generator tube rupture. Pittsburgh; United States, International Topical Meeting on Probabilistic Safety Assessment and Analysis, PSA 2017.

(Laskowski \& Hudson 1986) Laskowski, L. J., and M. J. B. Hudson 1986. Recirculating Steam Generator Corrosion at Northeast Utilities Nuclear Plants: A Review, presented at the Joint ASME/IEEE Power Generation Conference, Portland, Oregon, October 19-23, 1986, Paper 86JPGC-NE-4, American Society of Mechanical Engineers, New York.

(Lewandowski, 2013), Lewandowski, R., 2013. Incorporation of Corrosion Mechanisms into a State-dependent probabilistic risk assessment, Ohio: The Ohio State university.

(Lewandowski, et al., 2016), Lewandowski, R., Denning, R., Aldemir, T. \& Zhang, J., 2016. Implementation of condition-dependent probabilistic risk assessment using surveillance data on passive components. Annals of Nuclear Energy, Volume 87, pp. 696-706.

(Liu, et al., 2017), Liu, B. et al., 2017. Condition-based maintenance for systems with aging and cumulative damage based on proportional hazards model. Reliability Engineering \& System Safety, Volume 168, pp. 200-209.

(Luo, et al., 2016), Luo, L., Huang, Y., ShuoWeng \& Xuan, F.-Z., 2016. Mechanism-related modelling of pit evaluation in the CrNiMoV steel in simulated environment of low-pressure nuclear steam turbine. Materials and Design, Volume 105, p. 240-250.

(Mandelli, et al., 2018), Mandelli, D., Maljovec, D., Alfonsi, A., Parisi, C., Talbot, P., Cogliati, J., Smith, C.\& Rabiti, C., 2018. Mining data in a dynamic PRA framework. Progress in Nuclear Energy, Volume 108, pp. 99-110.

(Navidi \& Shayer, 2018), Navidi, W. \& Shayer, Z., 2018. An application of stochastic modeling to pitting of Spent Nuclear Fuel canisters. Progress in Nuclear Energy, Volume 107, pp. 48-56. 
(NRC, 1975), NRC, 1975. Reactor Safety Study: An assessment of accident risk in US commercial power plants (WASH-1400), Washington, DC: US Nuclear Regulatory Commission.

(NRC, 1983), NRC, 1983. PRA Procedures Guide, NUREG/CR-2300, Washington, DC: U.S. Nuclear Regulatory Commission.

(NRC, 2011), NRC, 2011. Probabilistic Risk Assessment and Severe Accident Evaluation, US-NRC.

(NUREG/CR-6365, 1996), NUREG/CR-6365, 1996. Steam Generator Tube Failures, Washington D.C.: U.S National Regulatory Commission.

(NUREG/CR-6664 , 2000), NUREG/CR-6664 , 2000. Pressure and Leak-Rate Tests and Models for Predicting Failure of Flawed Steam Generator Tubes: US Nuclear Regulatory Commission (USNRC).

(P.J.Millett \& Welty, 2012), P.J.Millett \& Welty, C., 2012. REVIEW of EPRI's steam generator $R \& D$ program, Palo Alto, CA: Electric Power Institute.

(Pla, et al., 2013), Pla, P., Reventós, F., Ramos, M. M. \& Sol, I., 2013. Analysis of steam generator tube plugging in A PWR. influence in the emergency operating procedures. Slovenia.

(Riznic, 2017), Riznic, J., 2017. Steam Generators for Nuclear Power Plants: Woodhead Publishing.

(Sattison \& Hall, 1990), Sattison, M. \& Hall, K., 1990. Analysis of Core Damage Frequency: Zion, Unit 1 Internal Events: NUREG/CR-4550, SAND86-2084 Vol. 7, Rev. 1 Part 1.

(Turnbull, et al., 2006), Turnbull, A., McCartney, L. N. \& Zhou, S., 2006. A model to predict the evolution of pitting corrosion and the pit-to-crack transition incorporating statistically distributed input parameters. Corrosion Science, 48(8), pp. 2084-2105.

(Valor, et al., 2007), Valor, A. et al., 2007. Stochastic modeling of pitting corrosion: A new model for initiation and growth of multiple corrosion pits. Corrosion Science, Volume 49, p. 559-579.

(Wade, 1995), Wade, K. C., 1995. Steam Generator Degradation and Its Impact on Continued Operation of Pressurized Water Reactors in the United States. Energy Information Administration.

(Wang, et al., 2016), Wang, W., Di Maio, F. \& Zio, E., 2016. Component-and system-level degradation modeling of digital Instrumentation and Control systems based on a Multi-State Physics Modeling Approach. Annals of Nuclear Energy, Volume 95, pp. 135-147.

(Yuan, et al., 2009), Yuan, X.-X., Mao, D. \& Pandey, M., 2009. A Bayesian approach to modeling and predicting pitting flaws in steam generator tubes. Reliability Engineering and System Safety, Volume 94, p. 1838-1847.

(Zhou \& Zhai, 2011), Zhou, B. \& Zhai, Z., 2011. Failure probabilistic analysis of steam generator heat-transfer tubing with pitting corrosion. Engineering Failure Analysis, 18(5), pp. 1333-1340.

(Zio, 2007), Zio, E., 2007. An Introduction to the Basics of Reliability and Risk Analysis: World Scientific Publishing Company.

(Zio, 2018), Zio, E., 2018. The Future of Risk Assessment. Reliability Engineering \& System Safety, Volume 177, pp. 176-190. 